\title{
Anticancer effect of S-allyl-L-cysteine via induction of apoptosis in human bladder cancer cells
}

\author{
JIN-NYOUNG HO ${ }^{1 *}$, MINYONG KANG $^{2 *}$, SANGCHUL LEE $^{1}$, JONG JIN OH ${ }^{1}$, \\ SUNG KYU HONG ${ }^{1}$, SANG EUN LEE ${ }^{1}$ and SEOK-SOO BYUN ${ }^{1}$ \\ ${ }^{1}$ Department of Urology, Seoul National University College of Medicine, Seoul National University Bundang Hospital, \\ Seongnam-si, Gyunggi-do 463-707; ${ }^{2}$ Department of Urology, Samsung Medical Center, Sungkyunkwan University School \\ of Medicine, Seoul 135-710, Republic of Korea
}

Received September 22, 2015; Accepted May 16, 2017

DOI: $10.3892 / \mathrm{ol} .2017 .7280$

\begin{abstract}
To examine the anticancer effects of S-allyl-L-cysteine (SAC) in human bladder cancer cells and to identify possible molecular mechanisms, bladder cancer cell lines (HTB5, HTB9, JON, UMUC14, T24, and cisplatin resistant-T24R2) were incubated with SAC, and cell proliferation was measured using the Cell Counting Kit-8 assay and clonogenic assay. Cell cycle and apoptosis were evaluated by flow cytometry. Expression levels of apoptosis- and cell cycle-associated proteins were analyzed by western blotting. Proliferation and colony formation in bladder cancer cells was significantly inhibited by SAC treatment in a dose-dependent manner. SAC treatment significantly enhanced apoptosis and promoted a cell cycle arrest in the $\mathrm{S}$ phase. SAC also increased the expression of apoptosis-related genes, including caspases, poly (ADP-ribose) polymerase and cytochrome c. SAC had an anticancer effect on bladder cancer cells in vitro, at least partially, through the induction of apoptosis and a cell cycle arrest. SAC is a potential therapeutic agent for the treatment of bladder cancer.
\end{abstract}

\section{Introduction}

Urinary bladder cancer is a common malignancy of the urinary tract and responsible for 150,000 deaths annually. Urinary bladder cancer is the seventh most prevalent type of cancer worldwide (1). In Korea, the number of cases of urinary bladder

Correspondence to: Professor Seok-Soo Byun or Professor Sangchul Lee, Department of Urology, Seoul National University College of Medicine, Seoul National University Bundang Hospital, 166 Gumi-ro, Bundang-gu, Seongnam-si, Gyunggi-do 463-707, Republic of Korea

E-mail: ssbyun@snubh.org

E-mail: uromedi@naver.com

*Contributed equally

Key words: bladder cancer cells, S-allyl-L-cysteine, anticancer, apoptosis, cell cycle cancer increased from 2,180 in 1999 to 3,549 in 2011 (2). The incidence of urinary bladder cancer is four times higher in men compared with women (3).

Cisplatin-based combination chemotherapy is widely used against advanced and metastatic bladder cancer. Such drugs, however, yield poor oncological outcomes and show high toxicity (4), and there is growing interest in other types of therapeutic agents for the treatment of advanced bladder cancer (4). The development of more effective and less toxic therapeutic regimens is vital for the improvement of survival among patients with bladder cancer.

Recent studies showed that natural bioactive compounds, including isothiocyanate and amygdalin, have anticancer effects on bladder cancer cells $(5,6)$. Garlic, a species of the Allium genus, has been utilized for medicinal purposes in recorded history (7-9). Organosulfur compounds from Allium vegetables have been reported to have possible preventive and therapeutic properties against some types of cancer (7). Sulfur-containing compounds in garlic can be broadly categorized as oil-soluble (diallylsulphide, diallyldisulphide and diallyltrisulfide) or water-soluble [S-allyl-L-cysteine (SAC)] (8). SAC is the most abundant organosulfur compound in aged-garlic extract and was reported to have antioxidant, and neuroprotective properties as well as anticancer activity (9-11). Several studies showed that SAC has anticancer effects by suppressing the cellular proliferation and metastasis and induces apoptosis in a number of cancer models, including ovarian, prostate and hepatocellular carcinoma (7-9). Nevertheless, whether SAC has anticancer effects in bladder cancer remains an open question.

In the present study, in vitro effects of SAC were evaluated by Cell Counting Kit-8 (CCK-8) assay, colony formation assay, cell cycle analysis and by measuring the expression of proteins associated with apoptosis and cell cycle in human bladder cancer cell lines, T24 and T24R2.

\section{Materials and methods}

Cell lines and reagents. Human bladder cancer cell lines HTB5, HTB9, J82, JON, UMUC14 and T24 were obtained from the American Type Culture Collection (Manassas, VA, USA). The cisplatin-resistant cell line T24R2 was generated by serial 
desensitization, as previously described (12). The cell lines (HTB5, HTB9, T24, and T24R2) were cultured in RPMI-1640 and the cell lines (J82, JON, and UMUC14) were cultured in Dulbecco's modified Eagle's medium supplemented with $10 \%$ fetal bovine serum and 1\% penicillin/streptomycin (all from Gibco; Thermo Fisher Scientific, Inc., Waltham, MA, USA) at $37^{\circ} \mathrm{C}$ in a humidified atmosphere incubator containing $5 \%$ $\mathrm{CO}_{2}$. SAC (PharmaKing Co., Ltd., Gyeonggi-do, Korea; Fig. 1) was diluted in dimethyl sulfoxide (DMSO; Sigma-Aldrich; Merck KGaA, Darmstadt, Germany) to obtain a $100 \mu \mathrm{M}$ stock solution and was then diluted to obtain the working concentration. The final concentration of DMSO in the culture media did not exceed $0.1 \%(\mathrm{v} / \mathrm{v})$. Media containing $0.1 \%$ DMSO was used as a control.

Cell proliferation assay. Cell proliferation was analyzed using the CCK-8 assay (Dojindo Molecular Technologies, Inc., Rockville, MD, USA) according to the manufacturer's instructions. Bladder cancer cells were seeded in 96-well plates at the density of $2 \times 10^{3} /$ well. After $24 \mathrm{~h}$, the cells were incubated at $37^{\circ} \mathrm{C}$ with $\mathrm{SAC}$ for 24,48 , or $72 \mathrm{~h}$. At the end of the drug exposure, $10 \mu$ l CCK- 8 solution was added to each well, which contains $200 \mu 1$ of the culture medium. After $4 \mathrm{~h}$ of incubation, the absorbance at $450 \mathrm{~nm}$ was measured on a plate reader (Molecular Devices, LLC, Sunnyvale, CA, USA). Cell viability was calculated as the percentage of viable cells in the total population. The experiment was performed in triplicate.

Clonogenic assay. T24 and T24R 2 cells were plated at $5 \times 10^{2}$ per 6-well plate and incubated with various concentrations of SAC (T24: 0, 10, 25 and $50 \mathrm{mM}$; T24R2: 0, 1, 5, 10 and $25 \mathrm{mM}$ ) for $48 \mathrm{~h}$. The cells were incubated at $37^{\circ} \mathrm{C}$ for another 14 days in the SAC-free medium. The cells were fixed with methanol and stained with a $0.1 \%$ crystal violet solution. The plates were photographed, and the colonies $>0.2 \mathrm{~mm}$ in diameter were counted.

Cell cycle analysis. T24 and T24R 2 cells were plated at $3 \times 10^{5}$ per $60 \mathrm{~mm}$ dish, grown for $24 \mathrm{~h}$ and then incubated at $37^{\circ} \mathrm{C}$ with various concentrations of SAC (T24: $0,10,25$ and $50 \mathrm{mM}$; T24R2: 0, 1, 5, 10 and $25 \mathrm{mM}$ ) for $48 \mathrm{~h}$. The cells were trypsinized and fixed in $70 \%$ ethanol and subsequently stained with a propidium iodide solution $(1 \mathrm{mg} / \mathrm{ml})$ for $30 \mathrm{~min}$ at $37^{\circ} \mathrm{C}$. The cell cycle distribution was determined using CellQuest Pro software (version 5.1) on a FACSCalibur instrument (both from BD Biosciences, San Jose, CA, USA).

Western blotting. The cells were lysed with radio immunoprecipitation assay (RIPA) buffer, consisting of $50 \mathrm{mM}$ Tris- $\mathrm{HCl}$ ( $\mathrm{pH} \mathrm{8.0)}, 150 \mathrm{mM}$ sodium chloride, $1.0 \%$ NP-40, $0.5 \%$ sodium deoxycholate, $0.1 \%$ SDS and $1 \mathrm{mM}$ phenylmethylsulfonyl fluoride. Protein concentrations were determined by using the BCA protein assay kit (Pierce; Thermo Fisher Scientific, Inc.). Equal amounts of total protein $(50 \mu \mathrm{g})$ were analyzed by SDS-PAGE (8 or 10\% gels) and then transferred onto polyvinylidene fluoride membranes (EMD Millipore, Billerica, MA, USA). The blots were blocked for $1 \mathrm{~h}$ with $5 \%(\mathrm{w} / \mathrm{v})$ non-fat dry milk at room temperature and then incubated with primary antibodies: Cleaved caspases-3,

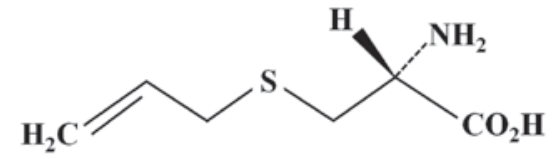

Figure 1. Structure of S-allyl-L-cysteine.

$-8,-9$, PARP, poly (ADP-ribose) polymerase, cytochrome c, Bcl-2, Bax, cyclins B1, D1, and E1, phosphorylated-AKT and AKT (Cell Signaling Technology, Inc., Danvers, MA, USA) overnight at $4^{\circ} \mathrm{C}$. After incubation with secondary antibodies (anti-mouse; catalog no. sc-2055; dilution, 1:10,000; and anti-rabbit; catalog no. sc-2004; dilution, 1:5,000; Santa Cruz Biotechnology, Inc., Dallas, TX, USA), protein expression was detected with enhanced chemiluminescence (ECL) Western blot substrate kit (Pierce; Thermo Fisher Scientific, Inc.) and quantified with ImageJ software (National Institute of Health, Bethesda, MA, USA).

Statistical analysis. The data are presented as mean \pm standard deviation of three independent experiments in triplicate. All calculations were performed using SPSS statistical software package (version 20.0; IBM Corp., Armonk, NY, USA). Statistical significance $(\mathrm{P}<0.05)$ was determined by Tukey's multiple comparison test.

\section{Results}

Treatment with SAC suppresses proliferation of human bladder cancer cells. To assess the effect of SAC on the growth of bladder cancer cells, CCK-8 assays were performed. As shown in Fig. 2, SAC markedly suppressed proliferation of bladder cancer cells in a time- and dose-dependent manner compared with untreated cells (control). Compared with the other cell lines (HTB9, JON, UMUC14 and T24), HTB5 and T24R2 were more sensitive to SAC treatment. The $50 \%$ inhibitory concentration $\left(\mathrm{IC}_{50}\right)$ of SAC toward $\mathrm{T} 24$ and T24R2 bladder cancer cells after $48 \mathrm{~h}$ of exposure was 52.98 and $19.87 \mathrm{mM}$, respectively. To evaluate the anti-proliferative effect of SAC on T24 and T24R2 cells, clonogenic assay was performed. The colony-forming ability of T24 and T24R 2 cells was significantly inhibited with increasing SAC concentrations in comparison with the control (Fig. 3). These data indicated that the SAC treatment may suppress the proliferation of bladder cancer cells in a dose-dependent manner.

Treatment with SAC induces alterations in cell cycle in bladder cancer cells. To elucidate the mechanism of SAC-induced proliferation inhibition, cell cycle distribution was detected by fluorescence-activated cell sorting (FACS) analysis. It was demonstrated that SAC markedly altered cell cycle progression of bladder cancer cell lines. Particularly, SAC markedly increased the sub-G1 cell population (which corresponds to apoptotic cells) in a dose-dependent manner (Fig. 4). The highest concentration of SAC (T24: $50 \mathrm{mM}$; T24R2: $25 \mathrm{mM}$ ) caused a 4.43 and 3.12-fold increase in the number of cells in the sub-G1 population in T24 and T24R2 cells, respectively, compared with the control. Of note, a statistically significant 
A

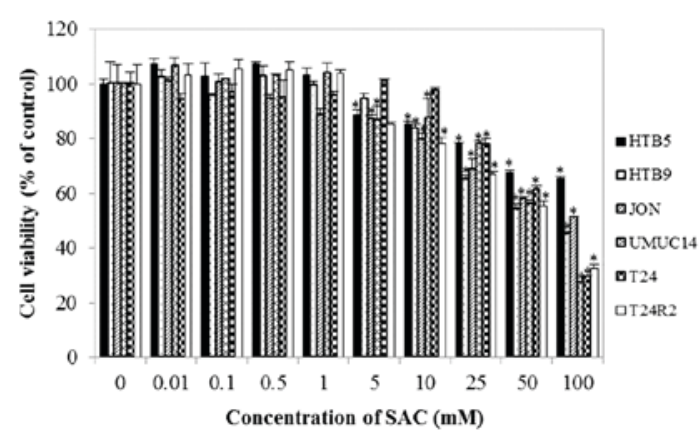

$\mathrm{C}$

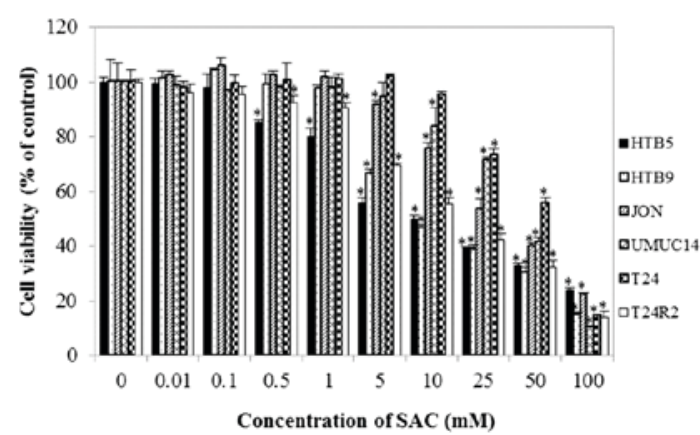

B

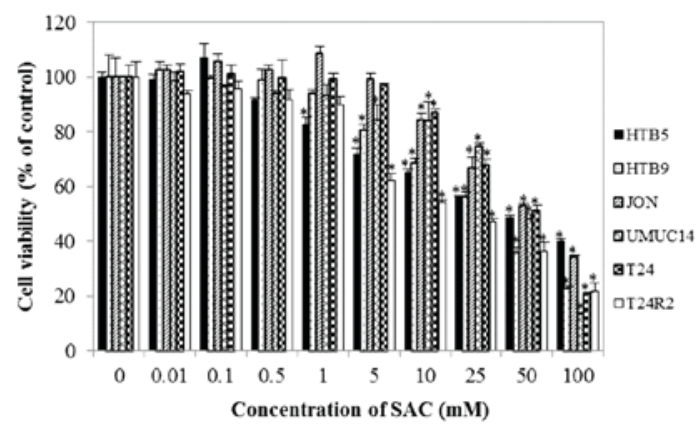

Figure 2. Effects of SAC on viability of bladder cancer cells. The cells were incubated with SAC for (A) $24 \mathrm{~h}$, (B) $48 \mathrm{~h}$ and (C) $72 \mathrm{~h}$. Cell viability was measured using Cell Counting Kit- 8 assay. Data are represented as the mean \pm standard deviation of three independent experiments. "P<0.05 vs. untreated control. SAC, S-allyl-L-cysteine.

A
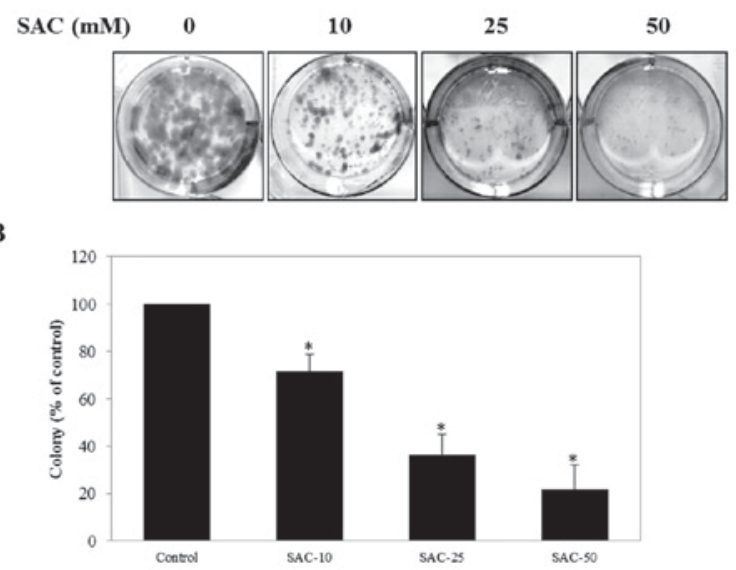

C

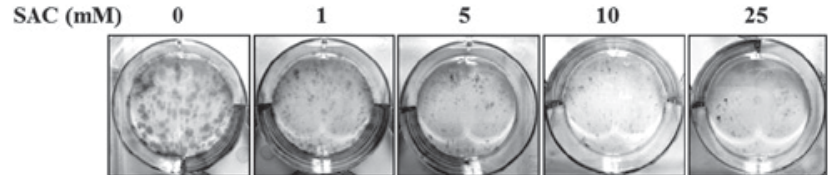

D

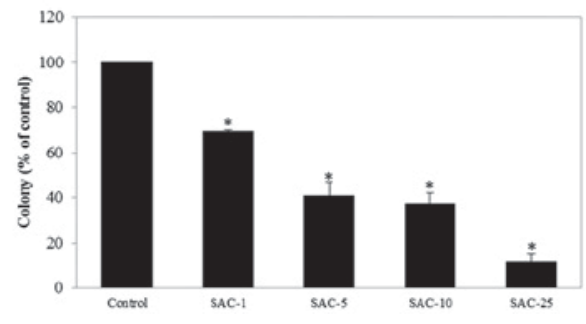

Figure 3. Effects of SAC on T24 and T24R2 cells according to a clonogenic assay. The cells were incubated with SAC for $48 \mathrm{~h}$ and were then cultured in fresh medium for 14 days to allow colonies to form. (A) Images of the clonogenic assay of T24 cells. (B) Graph showing the number of T24 cell colonies. (C) Images of the clonogenic assay of T24R2 cells. (D) Graph showing the number of T24R2 cell colonies. Data are represented as the mean \pm standard deviation of three independent experiments. "P<0.05 vs. untreated control. SAC, S-allyl-L-cysteine.

difference was observed in T24R2 cells treated with $25 \mathrm{mM}$ SAC compared with the control. Additionally, the S phase population was noticeably increased from 16.8 (untreated control) to $38.2 \%$ in T24R 2 cells treated with $25 \mathrm{mM}$ SAC. These results showed that SAC increased the sub-G1 population, which corresponds to apoptotic cells, in T24 and T24R2 bladder cancer cells.

Treatment with SAC alters expression of apoptosis and cell cycle-associated proteins in bladder cancer cells. To validate the effects of SAC on apoptosis and the cell cycle, western blot analysis was performed. The expression of caspases-3, -8, and -9; fragmented PARP and cytochrome $c$ was markedly increased with increasing SAC concentrations in T24 and T24R2 cells (Fig. 5). Additionally, the expression of the anti-apoptotic protein Bcl-2 was decreased following SAC treatment in T24 and T24R2 cells, whereas the expression of the pro-apoptotic protein Bax was increased.

In addition, as an index of S phase arrest (13), the expression of cyclins was measured. Treatment with SAC markedly downregulated cyclin B1, D1 and E1. AKT phosphorylation was also markedly suppressed by SAC in the bladder cancer 
A
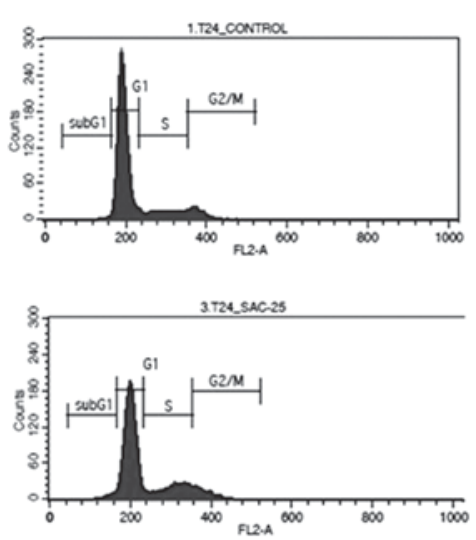
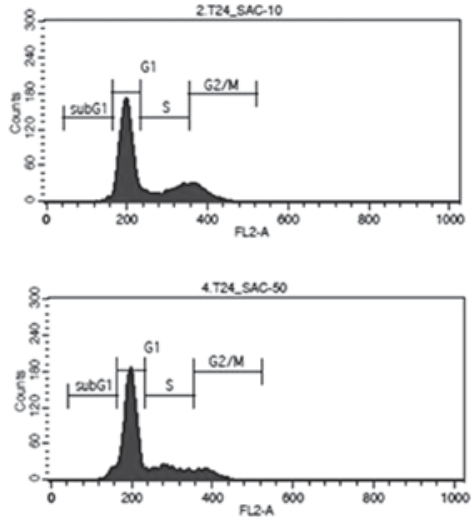

B
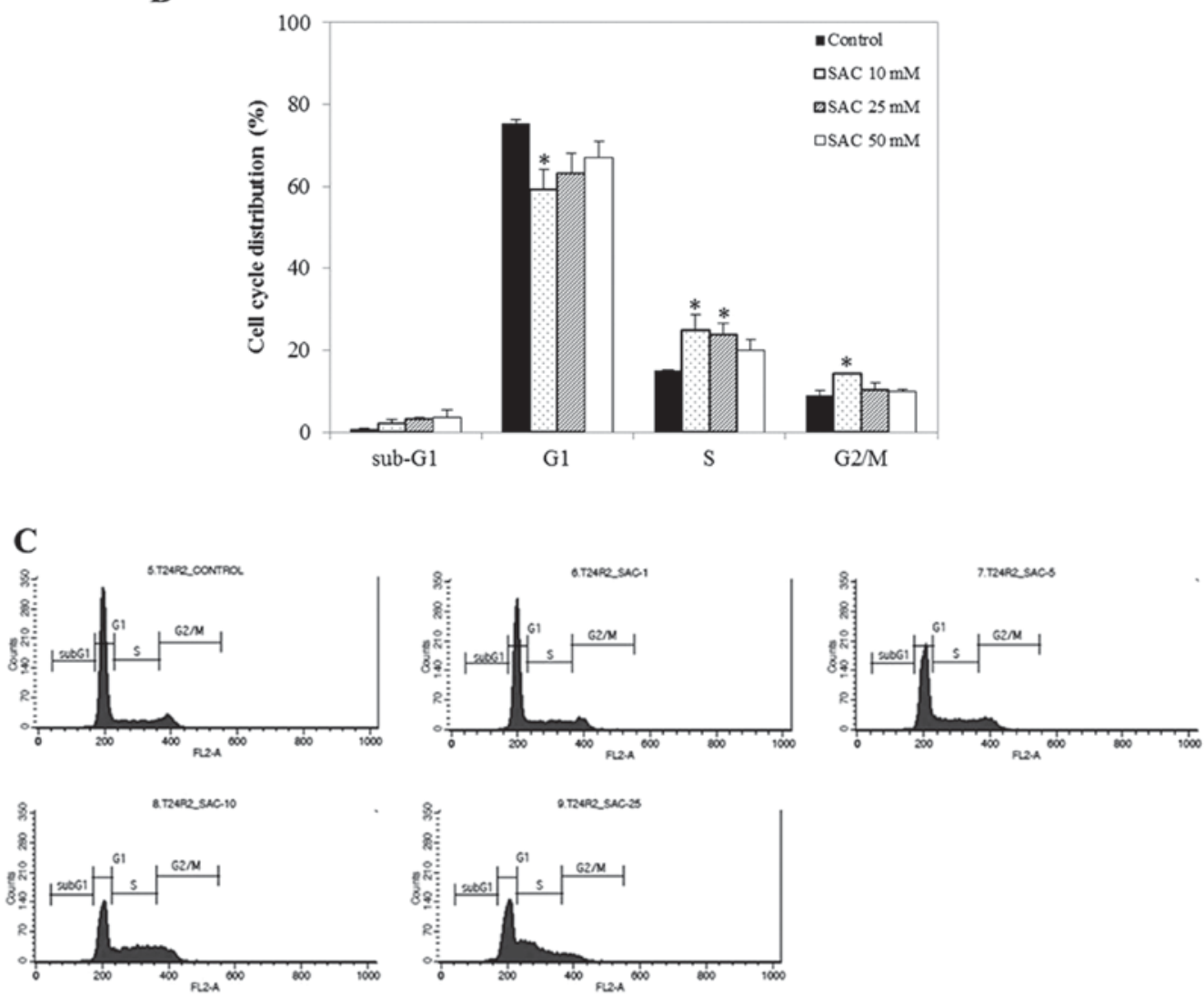

D

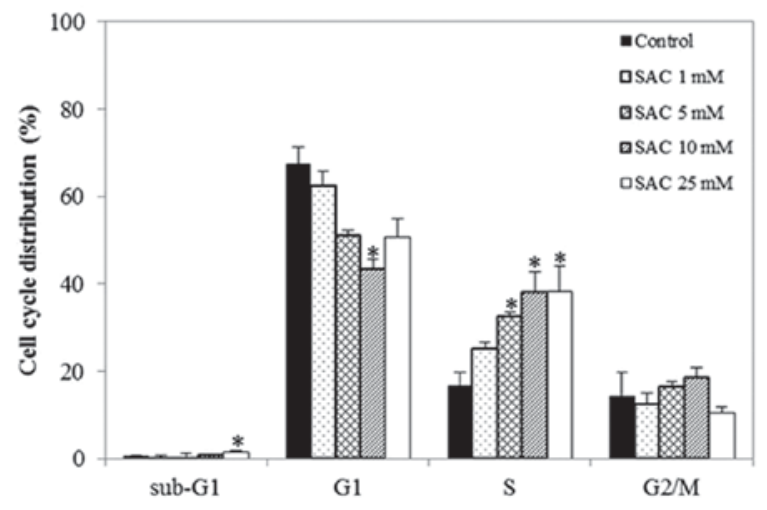

Figure 4. Effects of SAC on cell cycle progression in T24 and T24R2 cells. The cells were incubated with SAC for 48 h. (A) Flow cytometric DNA content histogram of T24 cells following treatment with 0,10,25 and $50 \mu \mathrm{M}$ SAC. (B) Quantitative measures of cycle alterations in T24 cells. (C) Flow cytometric DNA content histogram of T24R2. (D) Quantitative measures of cycle alterations in T24R2 cells following treatment with $0,1,5,10$ and $25 \mu \mathrm{M} \mathrm{SAC}$. Cellular DNA was stained with propidium iodide, and flow cytometric analysis was performed to evaluate the cell cycle distribution. Data are represented as the mean \pm standard deviation of three independent experiments. "P<0.05 vs. untreated control. SAC, S-allyl-L-cysteine. 
$\mathbf{A}$

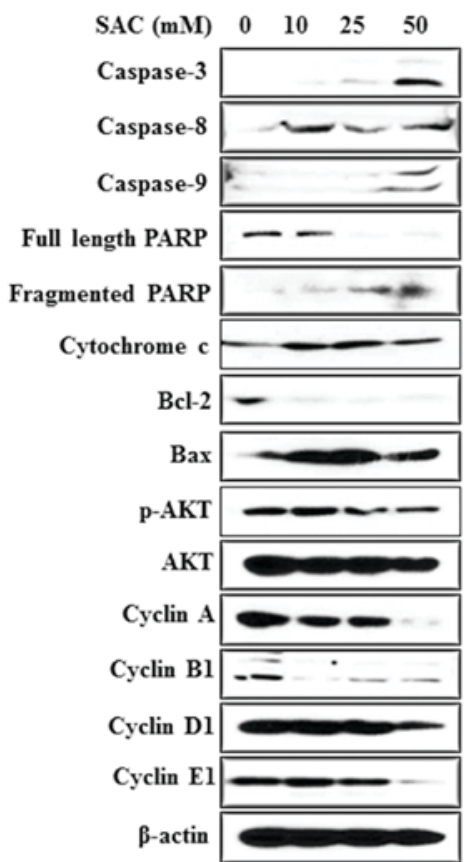

B

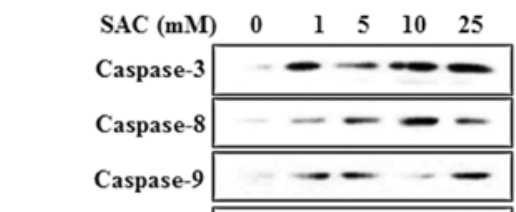

Full length PARP

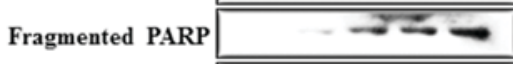

Cytochrome c $-\infty-\infty$

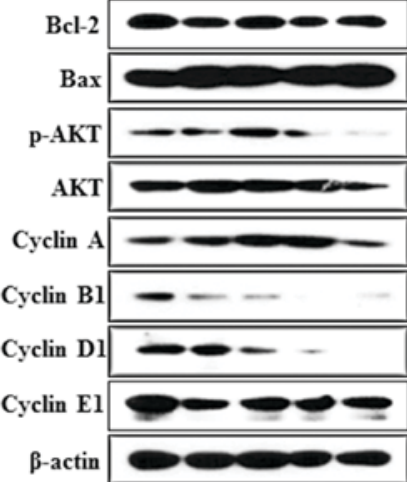

\section{C}

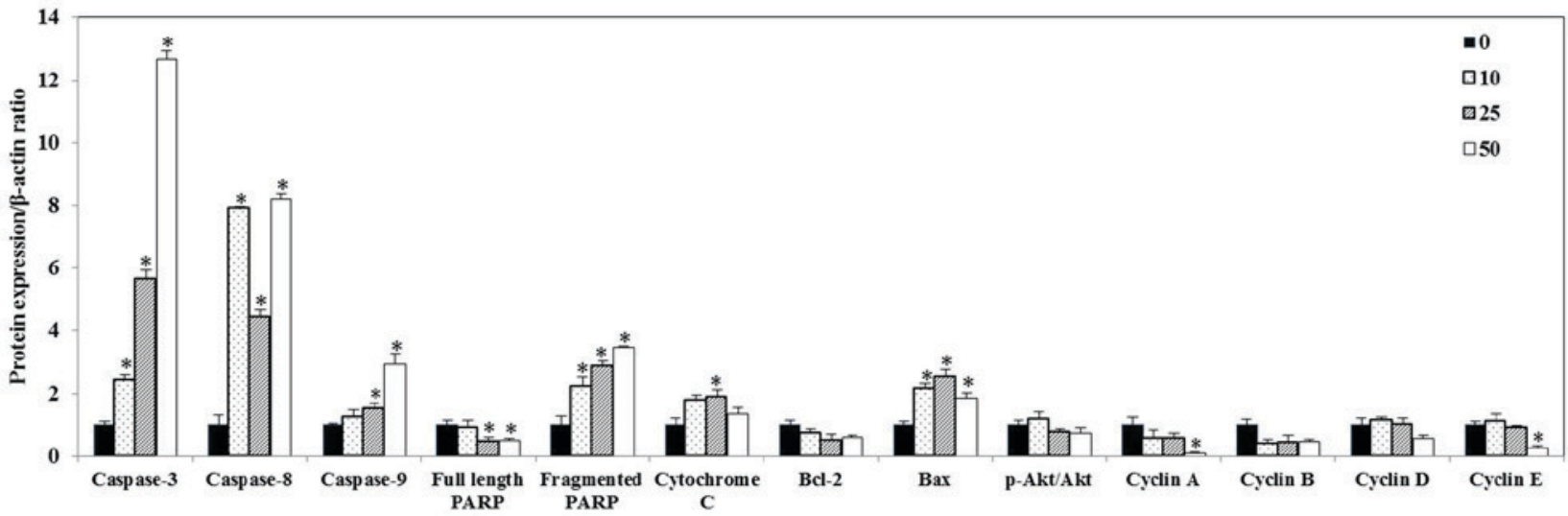

D

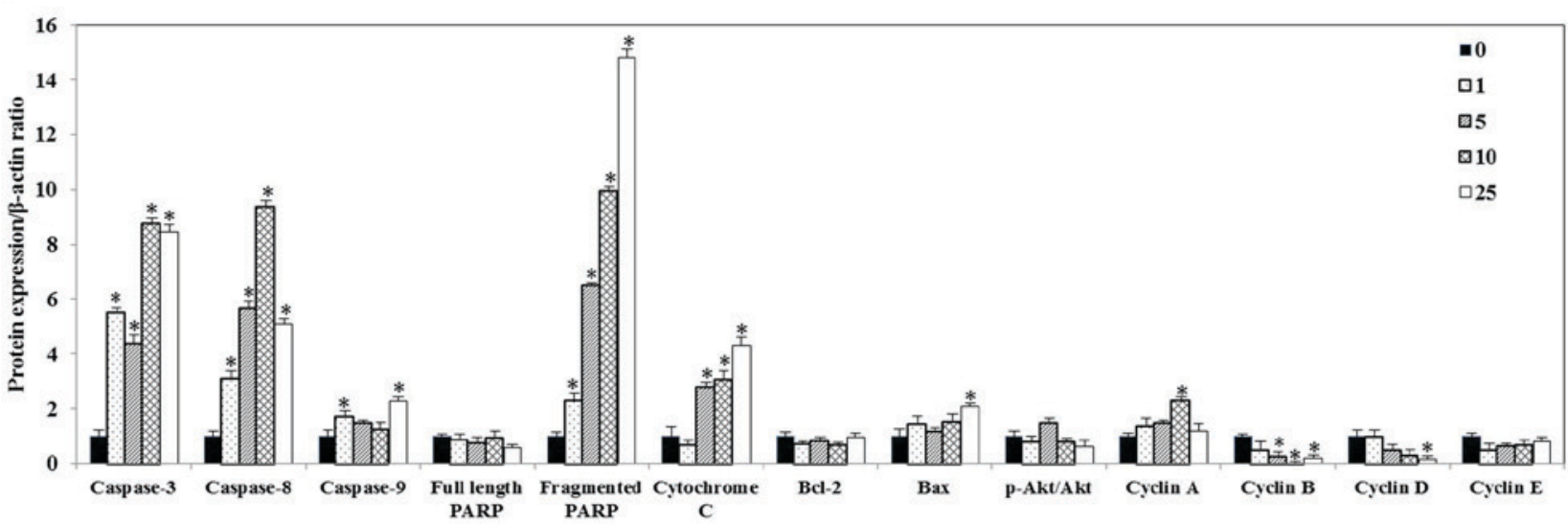

Figure 5. Effects of SAC on expression of apoptosis-associated proteins in (A and C) T24 and (B and D) T24R2 cells. The cells were incubated with SAC for $48 \mathrm{~h}$. Protein expression was analyzed by western blotting and quantified with ImageJ software. Equal amounts of total proteins were loaded onto the gels for SDS-PAGE. Data are represented as the mean \pm standard deviation of three independent experiments. ${ }^{*} \mathrm{P}<0.05$ vs. untreated control. Bcl-2, B-cell lymphoma 2; SAC, S-allyl-L-cysteine; p, phosphorylated; PARP, Poly (ADP-ribose) polymerase.

cells (Fig. 5). These results suggested that SAC inhibited the growth of bladder cancer cells via an apoptosis-associated mechanism and disrupted cell survival by inhibiting the AKT signaling pathway.

\section{Discussion}

Nowadays, cancer patients are interested in complementary and alternative medicine (CAM) because they do not like 
adverse effects of conventional medical treatment, and because of the need for personal control over treatment as well as, the perceived safety of a natural product $(14,15)$. In Europe, $>50 \%$ of cancer patients use CAM instead of or in combination with conventional medical treatment (6). CAM includes diet and nutritional interventions, music therapy and aromatherapy. Among these therapies, diet and nutritional therapies are most commonly used by cancer patients (14).

Recently, many studies showed that natural compounds, including (-)-epigallocatechin-3-gallate and resveratrol, induce cell death and cell cycle arrest in bladder cancer cells (16-18). In the present study, incubation of bladder cancer cell lines with SAC markedly reduced cell proliferation according to CCK- 8 and clonogenic assays in a time- and dose-dependent manner. SAC inhibited the proliferation of bladder cancer cells at least in part by inducing apoptosis, as evidenced by increase in the sub-G1 population. The data in the present study are consistent with the findings of another study, which showed that SAC exhibits its anticancer activity on prostate cancer cells and ovarian cancer cells by inducing apoptosis $(8,9)$. Altogether, these studies indicate that SAC may account for apoptosis in multiple cancer cells, including bladder cancer cells and contribute to suppressed cancer cell proliferation.

Cell cycle checkpoints are a key factor in cancer pathogenesis, and their dysregulation may affect the effectiveness of cancer chemotherapy. Numerous studies have shown that cancer progression involves the loss of checkpoint controls that regulate the passage through the cell cycle (19). Flow cytometry was used in the present study to identify the mechanism underlying the SAC-mediated inhibition of cell growth. Cell cycle arrest was detected in the $\mathrm{S}$ phase following treatment with SAC in bladder cancer cells, consistent with the findings of $\mathrm{Nq}$ et al (7) in hepatic cancer cells. In support of this hypothesis, it was also identified that SAC inhibits expression of cyclins B1, D1 and E1 in the bladder cancer cells. Taken together, the results in the present study indicated that SAC may inhibit cell growth in part by affecting apoptosis and the regulation of the cell cycle.

Overexpression of anti-apoptotic proteins including Bcl-2 and $\mathrm{Bcl}-\mathrm{xl}$ is often associated with tumor recurrence, poor prognosis and resistance to cancer treatment (20). Generally, cancer cells can inactivate apoptotic signaling pathways by overexpressing such anti-apoptotic proteins and via the down-regulation of pro-apoptotic proteins (including Bax and Bad) and the caspase family $(20,21)$. On the other hand, inhibition of the intrinsic apoptotic pathways is linked with activities of the AKT and NF- $\mathrm{KB}$ signaling pathways. The activated AKT pathway inhibits the intrinsic apoptotic pathway by upregulating anti-apoptotic proteins while downregulating pro-apoptotic proteins (21). To identify the possible mechanisms underlying the apparent anticancer effect of SAC, the expression of apoptosis-associated proteins, including PARP, caspases, Bcl-2, Bax, and AKT was examined. As expected, SAC treatment reduced phosphorylation of AKT. Furthermore, SAC markedly decreased the expression of Bcl-2, whereas the expression of Bax was increased in a dose-dependent manner, further confirming the promotion of apoptosis. There was also a change in the expression of PARP and caspases, in favor of apoptosis.

The results in the present study are consistent with the findings of Xu et al (8). Treatment of A2780 ovarian cancer cells with SAC induces $\mathrm{S}$ phase arrest and apoptosis, accompanied by reduced expression of $\mathrm{Bcl}-2$ and increased expression of caspase-3 and Bax (8). Accordingly, the authors of the present study hypothesize that SAC suppresses proliferation of T24 and T24R2 cells through the induction of apoptosis.

In conclusion, SAC inhibits cell proliferation and clonogenicity through the induction of apoptosis and cell cycle arrest by altering the expression of apoptosis and cell cycle regulators in bladder cancer cells. The findings of the present study suggest that SAC is a promising agent for the treatment of bladder cancer.

\section{Acknowledgements}

The present study was funded by a research grant from Ildong Pharmaceutical Co., Ltd. (grant no. 06-2015-028). SAC was supplied by PharmaKing Co., Ltd. (Gyeonggi-do, Republic of Korea).

\section{References}

1. Yun SJ and Kim WJ: Role of the epithelial-mesenchymal transition in bladder cancer: From prognosis to therapeutic target. Korean J Urol 54: 645-650, 2013.

2. Song W and Jeon HG: Incidence of kidney, bladder, and prostate cancers in Korea: An update. Korean J Urol 56: 422-428, 2015.

3. Arantes-Rodrigues R, Pinto-Leite R, Fidalgo-Gonçalves L, Palmeira C, Santos L, Colaço A and Oliveira P: Synergistic effect between cisplatin and sunitinib malate on human urinary bladder-cancer cell lines. Biomed Res Int 2013: 791406, 2013.

4. Pliarchopoulou K, Laschos K and Pectasides D: Current chemotherapeutic options for the treatment of advanced bladder cancer: A review. Urol Oncol 31: 294-302, 2013.

5. Sávio AL, da Silva GN and Salvadori DM: Inhibition of bladder cancer cell proliferation by allyl isothiocyanate (mustard essential oil). Mutat Res 771: 29-35, 2015.

6. Makarević J, Rutz J, Juenqel E, Kaulfuss S, Reiter M, Tsaur I, Bartsch G, Haferkamp A and Blaheta RA: Amygdalin blocks bladder cancer cell growth in vitro by diminishing cyclin A and cdk2. PLos One 9: e105590, 2014.

7. Nq KT, Guo DY, Cheng Q, Geng W, Ling CC, Li CX, Liu XB, Ma YY,Lo CM,Poon RT, et al: A garlic derivative, S-allylcysteine (SAC), suppresses proliferation and metastasis of hepatocellular carcinoma. PLoS One 7: e31655, 2012.

8. Xu YS, Feng JG, Zhang D, Zhang B, Luo M, Su D and Lin NM: S-allylcysteine, a garlic derivative, suppresses proliferation and induces apoptosis in human ovarian cancer cells in vitro. Acta Pharmacol Sin 35: 267-274, 2014.

9. Liu Z, Li M, Chen K, Yang J, Chen R, Wang T, Liu J, Yang W and Ye Z: S-allylcysteine induces cell cycle arrest and apoptosis in androgen-independent human prostate cancer cells. Mol Med Rep 5: 439-443, 2012.

10. Chung LY: The antioxidant properties of garlic compounds: Allyl cysteine, alliin, allicin, and allyl disulfide. J Med Food 9: 205-213, 2006.

11. Garcia E, Santana-Martinez R, Silva-Islas CA, Colín-González AL, Galván-Arzate S, Heras Y, Maldonado PD, Sotelo J and Santamaría A: S-allyl cysteine protects against MPTP-induced striatal and nigral oxidative neurotoxicity in mice: Participation of Nrf2. Free Radic Res 48: 159-167, 2014.

12. Byun SS, Kim SW, Choi H, Lee C and Lee E: Augmentation of cisplatin sensitivity in cisplatin-resistant human bladder cancer cells by modulating glutathione concentrations and glutathione-related enztme activities. BJU Int 95: 1086-1090, 2005. 
13. Yeo EJ, Ryu JH, Chun YS, Cho YS, Jang IJ, Cho H, Kim J, Kim MS and Park JW: YC-1 induces $S$ cell cycle arrest and apoptosis by activating checkpoint kinases. Cancer Res 66: 6345-6352, 2006.

14. Yu JS, Kim CB, Kim KK, Lee JE and Kim MY: Behaviors of providers of traditional korean medicine therapy and complementary and alternative medicine therapy for the treatment of cancer patients. J Pharmacopuncture 18: 27-35, 2015.

15. Stubbe CE and Valero M: Complementary strategies for the management of radiation therapy side effects. J Adv Pract Oncol 4: 219-231, 2013

16. Philippou Y,Hadjipavlou M, Khan S and Rane A: Complementary and alternative medicine (CAM) in prostate and bladder cancer. BJU Int 112: 1073-1079, 2013.

17. Chen JJ, Ye ZQ and Koo MW: Growth inhibition and cell cycle arrest effects of epigallocatechin gallate in the NBT-II bladder tumour cell line. BJU Int 93: 1082-1086, 2004.
18. Bai Y, Mao QQ, Qin J, Zheng XY, Wang YB, Yang K, Shen HF and Xie LP: Resveratrol induces apoptosis and cell cycle arrest of human T24 bladder cancer cells in vitro and inhibits tumor growth in vivo. Cancer Sci 101: 488-493, 2010.

19. Zhang K, Wu J, Wu X, Wang X, Wang Y, Zhou N, Kuo ML, Liu X, Zhou B, Chang L, et al: p53R2 inhibits the proliferation of human cancer cells in association with cell-cycle arrest. Mol Cancer Tehr 10: 269-278, 2011.

20. Goldar S, Khaniani MS, Derakhshan SM and Baradaran B: Molecular mechanisms of apoptosis and roles in cancer development and treatment. Asian Pac J Cancer Prev 16: 2129-2144, 2015.

21. Fiandalo MV and Kyprianou N: Caspase control: Protagonists of cancer cell apoptosis. Exp Oncol 34: 165-175, 2012. 